\title{
Effective and selective prevention of retinal leukostasis in streptozotocin-induced diabetic rats using gliclazide
}

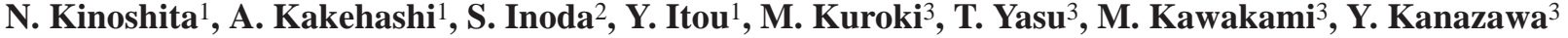 \\ ${ }^{1}$ Department of Ophthalmology, Omiya Medical Center, Jichi Medical School, Saitama, Japan \\ 2 Department of Ophthalmology, Jichi Medical School, Tochigi, Japan \\ ${ }^{3}$ Department of Comprehensive Medicine I, Omiya Medical Center, Jichi Medical School, 1-847 Amanuma, Saitama, \\ Saitama 330-8503, Japan
}

\begin{abstract}
Aims/hypothesis. Early stage leukocyte entrapment in the retinal microcirculation (retinal leukostasis) is considered to be one of the important pathogenetic events in diabetic retinopathy. Gliclazide, a sulphonylurea, was reported to reduce leukocyte adhesion to endothelial cells in hyperglycaemia in vitro, thus suggesting possible selective efficacy of this sulphonylurea in preventing leukostasis in diabetic patients. This study evaluated the effectiveness and selectivity of gliclazide treatment on retinal leukostasis of diabetic rats in vivo.

Methods. Streptozotocin (STZ) $(65 \mathrm{mg} / \mathrm{kg})$-induced diabetic rats were divided into three groups $(n=8$ each): an untreated diabetic group, a gliclazide-treated diabetic group, and a glibenclamide-treated diabetic group. Gliclazide or glibenclamide was administered orally during a 3-week period. Non-diabetic rats were used as a control $(n=8)$. Retinal leukostasis was quantitatively evaluated in vivo by acridine orange leukocyte fluorography using a scanning laser ophthalmoscope.
\end{abstract}

Results. The number of leukocytes trapped in the area around the optic disc in the untreated diabetic group $(36.9 \pm 5.1$ cells) increased significantly compared with the non-diabetic control group $(21.9 \pm 2.9$ cells; $p=0.0007)$. The number of leukocytes trapped in the gliclazide-treated diabetic group $(23.5 \pm 4.0$ cells $)$ decreased significantly compared with untreated diabetic group ( $p=0.0008)$. In contrast, no reduction of retinal leukostasis was found in the glibenclamide-treated diabetic group ( $37.8 \pm 5.8$ cells; $p=0.7923)$.

Conclusion/interpretation. This suggests that gliclazide could directly improve abnormalities in the retinal microcirculation independent of blood glucose control and possibly have selective therapeutic benefits in preventing early, critical events in diabetic retinopathy compared with other sulphonylurea drugs. [Diabetologia (2002) 45:735-739]

Keywords Gliclazide, sulphonylurea, diabetic retinopathy, retinal leukostasis, acridine orange leukocyte fluorography, scanning laser ophthalmoscope.
Diabetic retinopathy is a leading cause of adult vision loss and blindness and early-stage, preventive strategies are important research areas. Leukocyte adhesion

Received: 13 September 2001 / Revised: 21 January 2002

Published online: 5 April 2002

(C) Springer-Verlag 2002

Coresponding author: M. Kawakami, Department of Comprehensive Medicine I, Omiya Medical Center, Jichi Medical School, 1-847 Amanuma, Saitama, Saitama 330-8503, Japan e-mail: nobukawa@ omiya.jichi.ac.jp

Abbreviations: AOLF, Acridine orange leukocyte fluorography; SLO, scanning laser ophthalmoscope to the diabetic retinal vasculature is presumed to be the critical early event in the pathogenesis of diabetic retinopathy $[1,2,3]$, resulting in a breakdown in the blood-retinal barrier and in capillary nonperfusion [1, $4,5,6,7,8,9,10,11,12]$. In a rat model of diabetic retinopathy, investigators demonstrated retinal capillary occlusion by neutrophils and monocytes in histologic sections and found that areas of endothelial cell damage, capillary loss, and leukocyte extravasation existed adjacent to the static leukocytes [1]. In another post mortem study of human subjects, increased numbers of neutrophils were observed in the choroid and retina of patients with diabetes [2]. 
Gliclazide, a second generation sulphonylurea that has free radical scavenging activity $[13,14,15,16]$, is widely used for the treatment of Type II (non-insulindependent) diabetes mellitus. It was shown that enhanced adhesion of diabetic patients' monocytes to cultured bovine aortic endothelial cells was normalized after treating the patients with gliclazide [17]. In an in vitro study using gliclazide, lower adhesion of neutrophils to cultured endothelial cells was also shown [18]. These studies of gliclazide on leukocyte adhesion suggested a preventive effect of this drug on diabetic retinopathy.

This study aimed to evaluate quantitatively the effectiveness of gliclazide treatment on leukocyte entrapment in the retinal microcirculation (retinal leukostasis) in diabetes in vivo.

\section{Materials and methods}

Animals. All experiments followed the Association for Research in Vision and Ophthalmology (ARVO) Statement for the Use of Animals in Ophthalmic and Vision Research. Eightweek-old male Brown Norway rats weighing approximately $170 \mathrm{~g}(n=32)$ were used for this experiment. Rats $(n=24)$ received a single $65 \mathrm{mg} / \mathrm{kg}$ intravenous injection of streptozotocin (STZ; Sigma Chemical, St. Louis, Miss., USA) in $10 \mathrm{mmol} / \mathrm{l}$ sodium citrate buffer, $\mathrm{pH} 4.5$, after an overnight fast. Control, non diabetic rats $(n=8)$ received citrate buffer alone. We confirmed that the blood glucose concentration in each rat was over $350 \mathrm{mg} / \mathrm{dl} 48 \mathrm{~h}$ after injection by using a blood glucose measuring device (Glucocard GT-1640, Arkray, Kyoto, Kyoto, Japan). All rats had free access to water and food in an air conditioned room for 3 weeks, after which acridine orange leukocyte fluorography (AOLF) was done. STZinduced diabetic rats were divided into an untreated diabetic group $(n=8)$, a gliclazide-treated diabetic group $(n=8)$, and a glibenclamide-treated diabetic group $(n=8)$. Non-diabetic rats were used as a control group $(n=8)$. Gliclazide was given orally mixed with food at doses of about $150 \mathrm{mg} / \mathrm{kg}$ daily for 3 weeks, and glibenclamide was given in the same manner at doses of about $8.6 \mathrm{mg} / \mathrm{kg}$ daily for 3 weeks, starting $48 \mathrm{~h}$ after STZ administration.

Acridine orange leukocyte fluorography. Retinal leukostasis was quantitatively evaluated with AOLF using a scanning laser ophthalmoscope (SLO; Rodenstock Instruments, Munich, Bavaria, Germany) according to the method previously described $[19,20]$. Acridine orange is a dye that emits a green fluorescence when it interacts with DNA. An argon blue laser was used as the illumination source, with a regular emission filter for fluorescein angiography. The spectral properties of leukocytes stained with acridine orange are similar to those of sodium fluorescein. Using this method, an increase in the density of static leukocytes was shown in the retinas of STZ-induced diabetic rats $[3,10]$. Retinal leukostasis was evaluated in the right eye of each rat in each group after a 3-week period of diabetes. Immediately before AOLF, the rats were anaesthetized with pentobarbital $(37.5 \mathrm{mg} / \mathrm{kg})$ after aetherization. The pupil of the right eye was dilated with $0.5 \%$ tropicamide and $2.5 \%$ phenylephrine hydrochloride. A contact lens designed for rats (Unicon, Osaka, Osaka, Japan) was placed on the cornea to maintain transparency throughout the experiments. Acridine orange (Wako Pure Chemicals, Osaka, Osaka, Japan) was dis-

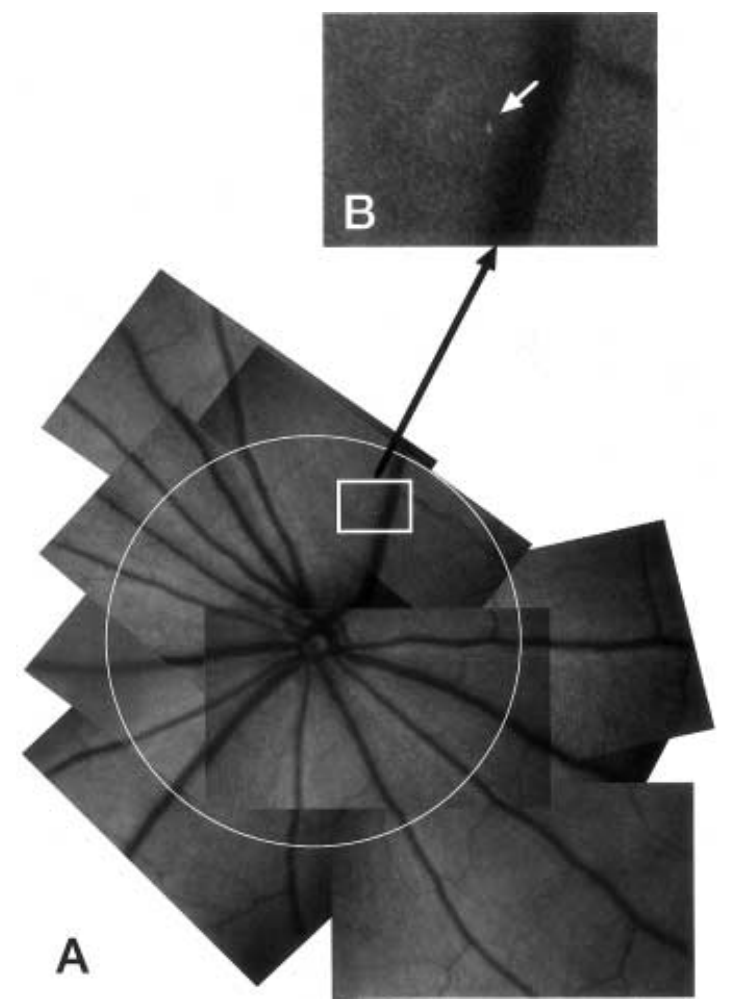

Fig. 1A, B. To evaluate retinal leukostasis, we produced a panoramic photograph from a digital image and counted the number of leukocytes trapped in the area around the optic disc (3 disc diameters in radius), 30 min after injection of acridine orange (A). Retinal leukostasis is observed as fluorescent dots $30 \mathrm{~min}$ after acridine orange injection. The arrow indicates a trapped leukocyte (B)

solved in sterile saline $(1.0 \mathrm{mg} / \mathrm{ml})$, and $3 \mathrm{mg} / \mathrm{kg}$ was injected through the tail vein at a rate of $1 \mathrm{ml} / \mathrm{min}$. A focused image of the peripapillary fundus of the right eye was obtained with the SLO. We confirmed the staining of leukocytes with acridine orange by direct observation of fluorescent leukocyte circulation throughout the retina immediately after the injection. Thirty minutes after the injection, the fundus was evaluated for retinal leukostasis by counting the number of leukocytes adhering on and extravasating from the endothelium of retinal capillaries. Leukocytes trapped in the retinal microcirculation were observed as fluorescent dots. The obtained images were stored on S-VHS videotape in order to replay and evaluate retinal leukostasis quantitatively. We digitized the video image to 640 horizontal and 480 vertical pixels with an intensity resolution of 256 steps. To evaluate the extent of retinal leukostasis, we produced a panoramic photograph from a digital image obtained $30 \mathrm{~min}$ after acridine orange injection and counted the number of leukocytes trapped in the area around the optic disc measuring three disc diameters in radius (Fig. 1).

Statistical analysis. The data are expressed as means \pm SD and compared by analysis with the Mann-Whitney U test. Differences were considered statistically significant when $p$ was less than 0.05 . 
Table 1. Blood glucose concentrations in peripheral blood

\begin{tabular}{|c|c|c|c|c|}
\hline & \multirow[t]{2}{*}{ Control $(n=8)$} & \multicolumn{3}{|c|}{ STZ-induced diabetic rats } \\
\hline & & $\begin{array}{l}\text { No treatment } \\
(n=8)\end{array}$ & $\begin{array}{l}\text { Gliclazide } \\
(n=8)\end{array}$ & $\begin{array}{l}\text { Glibenclamide } \\
(n=8)\end{array}$ \\
\hline $\begin{array}{l}\text { Blood glucose }(\mathrm{mg} / \mathrm{dl}) \text {, } \\
48 \mathrm{~h} \text { after STZ injection }\end{array}$ & $101.8 \pm 11.0$ & $429.4 \pm 28.7^{\mathrm{a}}$ & $424.5 \pm 31.4^{\mathrm{a}}$ & $429.1 \pm 34.9^{a}$ \\
\hline
\end{tabular}

${ }^{a} p<0.001$ compared with control rats at the same time period Values are means \pm SD
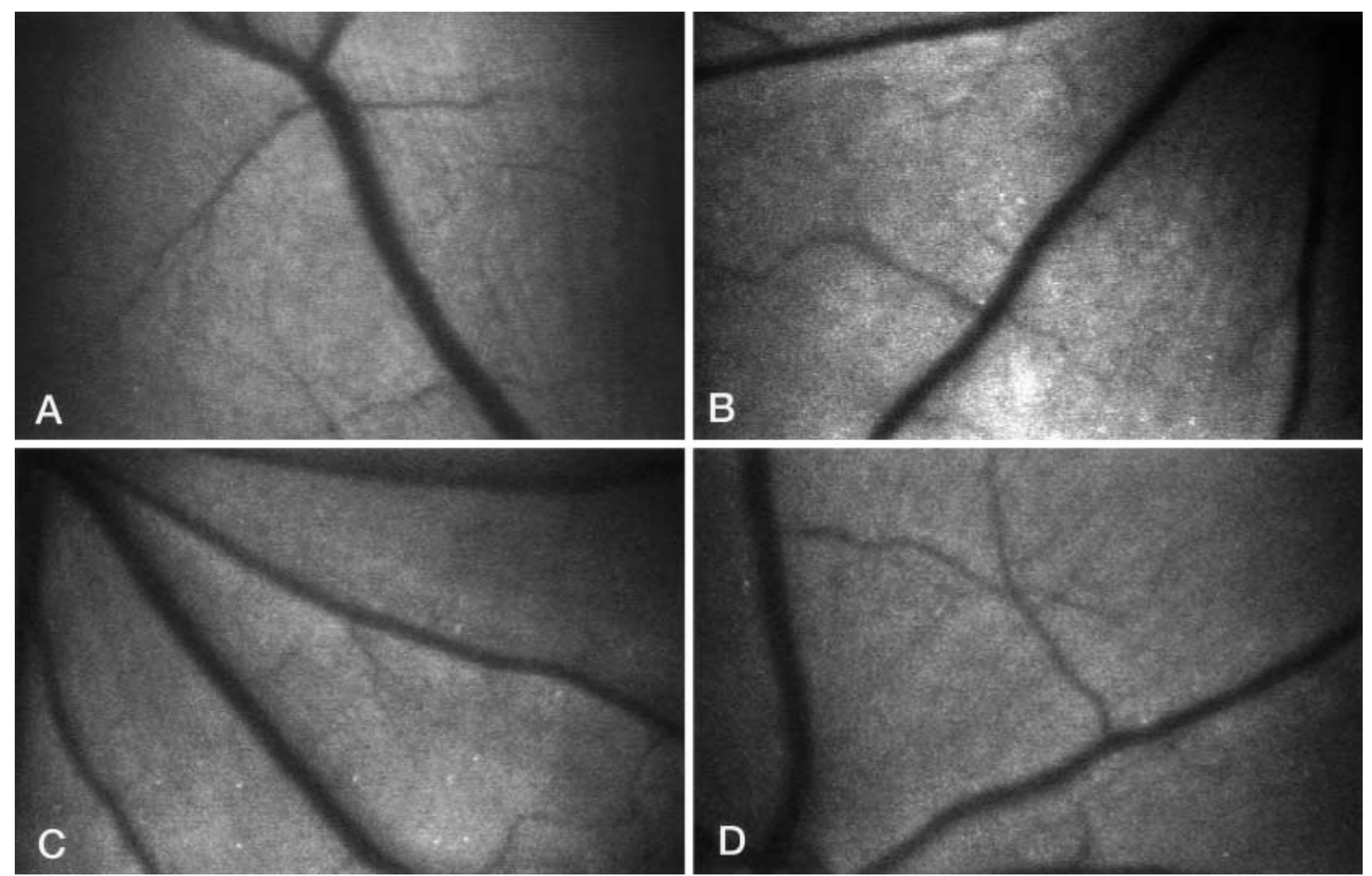

Fig. 2A-D. A small number of leukocytes are seen in the control rats (A). Retinal leukostasis was remarkably increased after 3 weeks of diabetes in the untreated diabetic rats and glibenclamide-treated rats $(\mathbf{B}, \mathbf{C})$. Leukostasis decreased remarkably in rats treated with gliclazide (D)

\section{Results}

The blood glucose concentrations of STZ-induced diabetic rats were higher than those of control rats $48 \mathrm{~h}$ and 3 weeks after the STZ injection $(p<0.001)$. There were no differences of blood glucose concentrations among the three groups of STZ-induced diabetic rats $(p>0.7)$ (Table 1$)$.

Fluorescence of circulating leukocytes was observed in the retinal circulation immediately after acri-

dine orange injection. However, the circulating fluorescence disappeared within several minutes and only the fluorescence of the trapped leukocytes remained in the retina as distinct fluorescent dots after $30 \mathrm{~min}$ when leukostasis was evaluated (Fig. 2).

Table 2 shows the number of leukocytes trapped in the area around the optic disc in the four groups of rats: the non-diabetic control group, the untreated diabetic group, the gliclazide-treated diabetic group, and the glibenclamide-treated diabetic group. In the untreated diabetic group, the number of trapped leukocytes $(36.9 \pm 5.1$ cells; $n=8)$ was increased significantly compared with the non-diabetic control group $(21.9 \pm 2.9$ cells; $n=8 ; p=0.0007)$. Oral administration of gliclazide resulted in a significant reduction of leukostasis in the diabetic retina $(23.5 \pm 4.0$ cells; 
Table 2. Numbers of leukocytes trapped in the area around the optic disc measuring three disc diameters in radius. $n=8$ rats per group

\begin{tabular}{|c|c|c|c|c|}
\hline & \multirow[t]{2}{*}{ Control } & \multicolumn{3}{|c|}{ STZ-induced diabetic rats } \\
\hline & & Untreated & Gliclazide & Glibenclamide \\
\hline $\begin{array}{l}\text { Statistical } \\
\text { comparison }\end{array}$ & $\begin{array}{l}p=0.0007 \text { vs } \\
\text { untreated group }\end{array}$ & & $\begin{array}{l}p=0.0008 \text { vs } \\
\text { untreated group }\end{array}$ & $\begin{array}{l}p=0.7923 \mathrm{vs} \\
\text { untreated group }\end{array}$ \\
\hline
\end{tabular}

$n=8)$ compared with the untreated diabetic group $(p=0.0008)$. In contrast, oral administration of glibenclamide did not reduce leukostasis in the retina significantly $(37.8 \pm 5.8$ cells; $n=8)$ compared with the untreated diabetic group $(p=0.7923)$.

\section{Discussion}

A number of previous reports have indicated the importance of leukocyte entrapment in the pathogenesis of diabetic retinopathy $[1,2,3,4,5,6,7,8,9,10,11$, 12] making leukocyte entrapment a therapeutic target for the prevention of this serious complication of diabetes. To date, only in vitro or ex vivo studies have been done that showed the inhibitory effects of gliclazide, a sulphonylurea hypoglycaemic drug, on enhanced adhesion of leukocytes to endothelial cells in high glucose conditions $[16,17,18]$. In this study, we clearly demonstrated the inhibition of leukostasis in the diabetic retina in vivo by gliclazide, but not by another sulphonylurea drug, glibenclamide, supporting these previous in vitro and ex vivo studies $[16,17,18]$ and explaining the observation in the previous clinical studies $[21,22]$ in which gliclazide actually showed a preventive effect on progression of diabetic retinopathy compared with other sulphonylurea drugs in diabetic patients.

AOLF used in this study was a simple, newly-established technique that is useful for the study of microcirculation in the retina $[3,7,10,19,20,23,24$, $25,26,27,28]$. Under the SLO, we observed directly the behaviour of circulating leukocytes in the retina. After a few minutes, the majority of circulating fluorescent leukocytes disappeared, and rolling cells on the endothelium also disappeared within the following $20 \mathrm{~min}$. By $30 \mathrm{~min}$ after dye injection, when retinal leukostasis was evaluated in this study, only cells adhering to endothelial cells and extravasating cells could be visualised. During the preparation of this manuscript, a similar study on gliclazide employing the same technique was reported from other laboratory in a meeting abstract [29].

Gliclazide is a member of the class of oral sulphonylurea drugs which lower blood glucose concentrations by stimulating insulin secretion from beta cells in the pancreas [30]. However, the effect of gliclazide on leukostasis shown in this study is not attributable to this principal mechanism of action of the agent, because the pancreas of STZ-induced diabetic rats is severely damaged and does not respond to any sulphonylurea agent [31] as is shown by the unchanged blood glucose concentrations of the three groups of STZ-diabetic rats after treatment with gliclazide or glibenclamide.

Gliclazide could have certain non-metabolic effects specifically related to vascular function, which other sulphonylurea agents might not have $[13,14,15,16$, $17,18,32,33,34]$. For example, gliclazide was reported to have free-radical scavenging activity [13, $14,15,16]$. It was shown that gliclazide reduced oxidized low-density lipoprotein (LDL)-induced monocyte adhesion to cultured endothelial cells as well as vascular cell-mediated LDL oxidation in vitro [16] and that gliclazide given to patients with Type II diabetes inhibits the increased adhesiveness of diabetic monocytes to cultured endothelial cells [17]. This radical-scavenging activity could be one of the mechanism of the inhibition of leukostasis observed in this study, because leukocytes in diabetic animals have been reported to be more activated $[1,4]$ and produce more oxygen-derived free radicals $[5,6]$, which induce vascular endothelial dysfunction $[7,8,9]$. Recent studies demonstrated the increased expression of adhesion molecules under diabetic conditions $[2,7,10$, $26,35]$. The interference by gliclazide with the increase in adhesion molecule expression could be another possibility, although it has not been examined in this study.

In conclusion, we showed that gliclazide attenuated retinal leukostasis irrespective of hyperglycaemia in the diabetic rat, whereas glibenclamide did not. This indicates that gliclazide, among other sulphonylurea drugs, might be selectively beneficial in preventing the development of diabetic retinopathy.

Acknowledgements. We thank Y. Takahashi, MD, K. Kasono, MD, H. Tamemoto, MD, K. Namai, MD, for their helpful suggestions. This study work was supported in part by a grant from Jichi Medical School as a Young Investigator's Award. 


\section{References}

1. Schroder S, Palinski W, Schmid-Schonbein GW (1991) Activated monocytes and granulocytes, capillary nonperfusion, and neovascularization in diabetic retinopathy. Am J Pathol 139:81-100

2. McLeod DS, Lefer DJ, Merges C, Lutty GA (1995) Enhanced expression of intracellular adhesion molecule- 1 and $\mathrm{P}$-selectin in the diabetic human retina and choroid. Am J Pathol 147:642-653

3. Miyamoto K, Hiroshiba N, Tsujikawa A, Ogura Y (1998) In vivo demonstration of increased leukocyte entrapment in retinal microcirculation of diabetic rats. Invest Ophthalmol Vis Sci 39:2190-2194

4. Wierusz-Wysocka B, Wysocki H, Siekierka H, Wykretowicz A, Szczepanik A, Kilmas R (1987) Evidence of polymorphonuclear neutrophils (PMN) activation in patients with insulin-dependent diabetes mellitus. J Leukoc Biol 42:519523

5. Freedman SF, Hatchell DL (1992) Enhanced superoxide radical production by stimulated polymorphonuclear leukocytes in a cat model of diabetes. Exp Eye Res 55:767-773

6. Ohmori M, Harada K, Kitoh Y, Nagasaka S, Saito T, Fujimura A (2000) The functions of circulatory polymorphonuclear leukocytes in diabetic patients with and without diabetic triopathy. Life Sci 66:1861-1870

7. Miyamoto K, Ogura Y (1999) Pathogenetic potential of leukocytes in diabetic retinopathy. Semin Ophthalmol 14: 233-239

8. Tesfamariam B, Cohen RA (1992) Free radicals mediate endothelial cell dysfunction caused by elevated glucose. Am J Physiol 263:H321-H326

9. Zanetti M, Sato J, Katusic ZS, O'Brien T (2001) Gene transfer of superoxide dismutase isoforms reverses endothelial dysfunction in diabetic rabbit aorta. Am J Physiol Heart Circ Physiol 280:H2516-H2523

10. Miyamoto K, Khosrof S, Bursell SE et al. (1999) Prevention of leukostasis and vascular leakage in streptozotocininduced diabetic retinopathy via intercellular adhesion molecule-1 inhibition. Proc Natl Acad Sci USA 96:1083610841

11. Lutty GA, Cao J, McLeod DS (1997) Relationship of polymorphonuclear leukocytes to capillary dropout in the human diabetic choroid. Am J Pathol 151:707-714

12. Linsenmeier RA, Braun RD, McRipley MA et al. (1998) Retinal hypoxia in long-term diabetic cats. Invest Ophthalmol Vis Sci 39:1647-1657

13. Jennings PE, Scott NA, Saniabadi AR, Belch JJ (1992) Effects of gliclazide on platelet reactivity and free radicals in type II diabetic patients: clinical assessment. Metabolism 41:36-39

14. Noda Y, Mori A, Packer L (1997) Gliclazide scavenges hydroxyl, superoxide and nitric oxide radicals: an ESR study. Res Commun Mol Pathol Pharmacol 96:115-124

15. O'Brien RC, Luo M, Balazs N, Mercuri J (2000) In vitro and in vivo antioxidant properties of gliclazide. J Diabetes Complications 14:201-206

16. Desfaits AC, Serri O, Renier G (1997) Gliclazide decreases cell-mediated low density lipoprotein (LDL) oxidation and reduces monocyte adhesion to endothelial cells induced by oxidatively modified LDL. Metabolism 46:1150-1156

17. Desfaits AC, Serri O, Renier G (1998) Normalization of plasma lipid peroxides, monocyte adhesion, and tumor necrosis factor- $\alpha$ production in NIDDM patients after gliclazide treatment. Diabetes Care 21:487-493
18. Okayama N, Oomi J, Shimizu M et al. (2000) Effect of high glucose level to the adhesion between neutrophil and vascular endothelial cell. Journal of the Japan Diabetes Society 43:341 (Abstract)

19. Nishiwaki H, Ogura Y, Kimura H, Kiryu J, Honda Y (1995) Quantitative evaluation of leukocyte dynamics in retinal microcirculation. Invest Ophthalmol Vis Sci 36: 123-130

20. Nishiwaki H, Ogura Y, Kimura H, Kiryu J, Miyamoto K, Matsuda N (1996) Visualization and quantitative analysis of leukocyte dynamics in retinal microcirculation of rats. Invest Ophthalmol Vis Sci 37:1341-1347

21. Akanuma Y, Kosaka K, Kanazawa Y, Kasuga M, Fukuda M, Aoki S (1988) Long-term comparison of oral hypoglycemic agents in diabetic retinopathy. Gliclazide vs. other sulphonylureas. Diabetes Res Clin Pract 5:81-90

22. Akanuma Y, Kosaka K, Kanazawa Y, Kasuga M, Fukuda M, Aoki S (1991) Diabetic retinopathy in non-insulindependent diabetes mellitus patients: the role of gliclazide. Am J Med 90:74S-76S

23. Kimura H, Kiryu J, Nishiwaki H, Ogura Y (1995) A new fluorescent imaging procedure in vivo for evaluation of the retinal microcirculation in rats. Curr Eye Res 14:223-228

24. Hamada M, Ogura Y, Miyamoto K, Nishiwaki H, Hiroshiba N, Honda Y (1997) Retinal leukocyte behavior in experimental autoimmune uveoretinitis of rats. Exp Eye Res 65:445-450

25. Tsujikawa A, Ogura Y, Hiroshiba N, Miyamoto K, Kiryu J, Honda Y (1998) In vivo evaluation of leukocyte dynamics in retinal ischemia reperfusion injury. Invest Ophthalmol Vis Sci 39:793-800

26. Miyamoto K, Ogura Y, Hamada M et al. (1998) In vivo neutralization of P-selectin inhibits leukocyte-endothelial interactions in retinal microcirculation during ocular inflammation. Microvasc Res 55:230-240

27. Barouch FC, Miyamoto K, Allport JR et al. (2000) Integrin-mediated neutrophil adhesion and retinal leukostasis in diabetes. Invest Ophthalmol Vis Sci 41:1153-1158

28. Nonaka A, Kiryu J, Tsujikawa A et al. (2000) PKC- $\alpha$ inhibitor (LY333531) attenuates leukocyte entrapment in retinal microcirculation of diabetic rats. Invest Ophthalmol Vis Sci 41:2702-2706

29. Morita H, Tamai K, Matsuda Y et al. (2001) Glyclazid inhibits leukocyte entrapment irrespective of blood glucose level in retinal microcirculation of diabetic rats. Invest Ophthalmol Vis Sci 42 [Suppl] S207 (Abstract)

30. Chiasson JL, Hamet P, Verdy M (1991) The effect of Diamicron on the secretion and action of insulin. Diabetes Res Clin Pract 14:S47-S52

31. Yamamoto H, Uchigata Y, Okamoto H (1981) Streptozotocin and alloxan induce DNA strand breaks and poly (ADPribose) synthetase in pancreatic islets. Nature 294:284-286

32. Fu ZZ, Yan T, Chen YJ, Sang JQ (1992) Thromboxane/prostacyclin balance in type II diabetes: gliclazide effects. Metabolism 41 [Suppl 1]:33-35

33. Pagano PJ, Griswold MC, Ravel D, Cohen RA (1998) Vascular action of the hypoglycaemic agent gliclazide in diabetic rabbits. Diabetologia 41:9-15

34. Qiang X, Satoh J, Sagara M et al. (1998) Gliclazide inhibits diabetic neuropathy irrespective of blood glucose levels in streptozotocin-induced diabetic rats. Metabolism 47: 977-981

35. Morigi M, Angioletti S, Imberti B et al. (1998) Leukocyteendothelial interaction is augmented by high glucose concentrations and by perglycemia in a NF-kB-dependent fashion. J Clin Invest 101:1905-1915 